Dig Dis 1997; 15:124

\title{
Esophageal Intramural Pseudodiverticulosis
}

S.R.

Sami R.
Achem

Division of Gastroenterology, University of Florida, Jacksonville, Fla., USA

Sami R. Achem, MD, Division of Gastroenterology, Room 3045, University of Florida, 653 West 8th Street, Jacksonville, FL 32209-6511 (USA)

A 65-year-old woman complained of dysphagia. Endoscopy revealed typical pseudodiverticuli and esophageal candidiasis.

KARGEH

E-Mail karger@karger.ch Fax + 41613061234 http:// www. karger. ch

(C) 1997 S. KargerAG, Basel 0257-2753/97/0151-0124S12.00/0 